\title{
Technology acceptance drivers for AR smart glasses in the middle east: A quantitative study
}

\author{
Abdulla Alsharhan ${ }^{a *}$, Said A. Salloum ${ }^{b, c}$ and Ahmad Aburayya ${ }^{d}$ \\ ${ }^{\text {a }}$ Faculty of Engineering \& IT, The British University in Dubai, United Arab Emirates \\ ${ }^{b}$ School of Science, Engineering, and Environment, University of Salford, United Kingdom \\ ${ }^{c}$ Machine Learning and NLP Research Group, University of Sharjah, Sharjah, United Arab Emirates \\ ${ }^{d}$ Doctor of Quality \& Operation Management, Quality \& Corporate Development Office, Dubai Health Authority, Dubai, United Arab Emirates
}

\section{H R O N I C L E A B S T RACT}

Article history:

Received: June 18, 2021

Received in revised format: June 29,2021

Accepted: September 6, 2021

Available online: September 9, 2021

Keywords:

Augmented Reality

Smart Glasses

ARSG

Technology Acceptance Model

Technology Adoption

Intention to Use Technology

Wearable

Clustering

Factor Analysis

Persona

Middle East

\begin{abstract}
This study aims to establish Middle East users' perspectives on the major factors that impact their decision to adopt Augmented Reality AR smart glasses (ARSG). Thus, an online questionnaire was designed and sent directly to the respondents, and 584 valid data points were collected from individuals living in the Middle East. The data were analyzed using Pearson correlations and Exploratory Factor Analysis (EFA) techniques using SPSS. Eleven hypotheses were tested using Multiple Regression analysis, where seven independent variables out of eleven were confirmed to have a significant impact on the perceived adoption of ARSG. The results indicate that four of the independent variables including Pre-Market Knowledge, Image, Own privacy and Technology innovativeness show the significant impact on ARSG adoption at the 1\% significant level. In addition, the results indicate that three of the social and technological factors include Perceived Ease of use, Perceived usefulness and Other's privacy show the significant effect on ARSG adoption at the 5\% significant level. Among the 7 social and technological factors, the results suggest that technology innovation expresses the strongest effect on ARSG adoption with the highest coefficient value of $0.413(b=$ $0.413, \mathrm{t}=12.881, \rho<0.01$ ). Moreover, user intention is significantly impacted by gender and place of living but not by education or age. The research also provides pre-market insights on users' personal types that represent who will most likely adopt the new smart glasses and that differentiate them based on their priorities. To the best of our knowledge, this is among the first works to investigate technology acceptance drivers of AR smart glasses in the Middle East.
\end{abstract}

\section{Introduction}

The emergence of new communication technology has significantly impacted the way businesses and individuals interact with one another (Salloum et al., 2017; Aburayya et al., 2020a; Al-Maroof et al., 2021a,b; Alaali et al., 2021; Al Kurdi et al., 2021; Salloum et al., 2021; Taryam et al., 2021). Consumers are always online and, in all places, (Al-Khayyal et al., 2020). Augmented Reality Smart Glasses (ARSG) are one of the latest developments in communication technology. ARSG can refer to wearable Augmented Reality (AR) devices that are worn like ordinary glasses, and integrate virtual and physical information into a user's view field" (Rauschnabel, Brem \& Ro, 2015). Virtual and ARSG integrate augmented reality and wearable device characteristics, two widely yet individually-researched topics (Rauschnabel, He \& Ro, 2018). Tech giant companies such as Google, Apple, Microsoft, and Facebook were engaged in presenting different smart glasses solutions using cutting-edge technology (Elmqaddem, 2019). Some believe that ARSG will be the next big thing and define the next generation of media. The application of smart glasses can be utilized in many fields such as in tourism, where virtual information can be displayed in the physical environment. Another example is in a cultural building where visitors can navigate museums and get information during their tour. ARSG can also be applied in a medical settings such as fostering international collaborations during * Corresponding author. Tel.: +971506305997

E-mail address: alsharhan@outlook.com (A. Alsharhan)

(C) 2022 by the authors; licensee Growing Science, Canada. doi: $10.5267 /$ j.ijdns.2021.9.008 
surgery (Khor et al., 2016; Alshurideh et al., 2018; Taryam et al., 2020) and documentation purposes in forensic medicine (Albrecht et al., 2014), or in business settings by allowing real-time collaboration in product development (AlSuwaidi et al., 2021; Mouzaek et al., 2021). Although introducing "Google Glass" (Project Aura) lasted for a short period of time, it led to significant consequences that drove societies to think of the etiquette and ethics of using smart glasses in public. The first generation of ARSG such as "Google Glass" may have been ahead of its time, with some design and social issues (Healey \& Stephens 2017), but the next generation of ARSG are anticipated to overcome first generation shortfalls such as people's skeptical reaction, battery life, bulky design, small display, and the limited range of Apps. Little is known about users' intentions to utilize smart eyewear. Some theories attempt to explain users' motivations for adopting such new technologies. One of them is the technology acceptance model (TAM), which is a theory in information systems that describes how consumers come to accept and use technology (Alshurideh et al., 2019; Al Kurdi et al., 2020). Diffusion of innovations is a theory that attempts to explain how, why, and how quickly new ideas and technologies spread. Understanding who the innovators and early adopters are and why they want to use smart glasses may considerably accelerate distribution.

This study aims to establish the user's perspective on the major factors that impact his or her decision to adopt ARSG, and if these factors are significantly impacted by gender, education, age, or the place of living on intention to adopt ARSG. Moreover, we also aim to understand whether any of these factors can be clustered together to form different personas of users who will most likely adopt the ARSG. The remainder of the paper is structured as to present a review of the related literature, research methodology, results and their discussion, conclusion, limitations, and future research opportunities.

\subsection{Background}

In 2013, Google released the first known prototype of smart glasses called "Google Glass" to developers and a small number of customers. It was planned to go public on May 2014, but the device faced several criticisms, the most critical one was its potential privacy violation due to its integrated camera. The public version was discontinued in 2015. However, in 2017, Google announced an enterprise edition, followed by a second edition in 2019 tailored for enterprises as well (Kothari, 2019). Google continued its efforts to focus on business and industrial applications, where several companies thought this would be the promising market for ARSG. Microsoft deployed their smart glasses device "HoloLens" (Project Baraboo) in 2019 with vast promising industrial applications such as for medical and defense sectors. In 2021, Microsoft won a USD 21.88 billion deal over 10 years to ship 120,000 HoloLens glasses for US military use, in an effort to improve soldier readiness (Novet, 2021). Lenovo was also heading to the enterprise sector with their unique smart glasses solution. In 2019, they introduced "Think Reality A3". Lenovo's ARSG device is aimed at the new trend of distributed workforces and hybrid work models. Think Reality A3 creates a virtual private 1080p monitor for those who want to create their private workspace anywhere (i.e., at cafés or public places), offering the user to work on up to 5 virtual monitors side by side (StoryHub 2021). In contrast, some companies did not yet lose hope in the consumer market. In 2016, Snap Inc. made its debut into the smart glasses market with Spectacles, followed by a second generation in 2018. Despite their bold move, several media outlets reported that Snapchat overestimated the demand, where less than $50 \%$ of buyers kept using the Spectacles after a month of purchase (Heath, 2017). Regardless of the reported low adoption, Snap has continued to launch their third (2019) and fourth (2021) generation devices, which can integrate AR capability for the first time. Unlike the usual bulky ARSG designs, the new glasses looked like regular sunglasses, which might create a significant shift in how people interact with computers (Heath, 2021). In 2020, Jio, the primary operator in India and one of the world's leading operators (also backed by both Google and Facebook), announced Jio Glass, a mixed reality headset targeting the enterprise and education sectors. Facebook is also planning to enter the AR glasses market by releasing new smart glasses created with Luxottica's Ray-Ban in 2021 (Wagner \& Frier, 2021). The most anticipated ARSG comes from Apple, where it is reported that they are working on its AR glasses, allowing integrating maps, text messages, and apps in the physical environment, which is expected to hit the market by 2023 (Haselton, 2019 ). The current Apple Glass prototype is fundamentally different from other ARSG solutions because it does not include a camera for privacy reasons. Instead, it has a LiDAR scanner on the right temple, but these features could change in the final design (Phelan, 2020).

\section{Literature review}

\subsection{Theoretical framework}

Media devices have gone through drastic changes, from offline mediums such as CD-ROMs, to always and everywhere online devices such as the mobile social web. The upcoming media generation is the next one, where offline $=$ online (Figure 5). This is also known as Wearable Augmented Reality Devices (WARDs), which represents the fifth generation of media (Rauschnabel, Brem \& Ro 2015). 


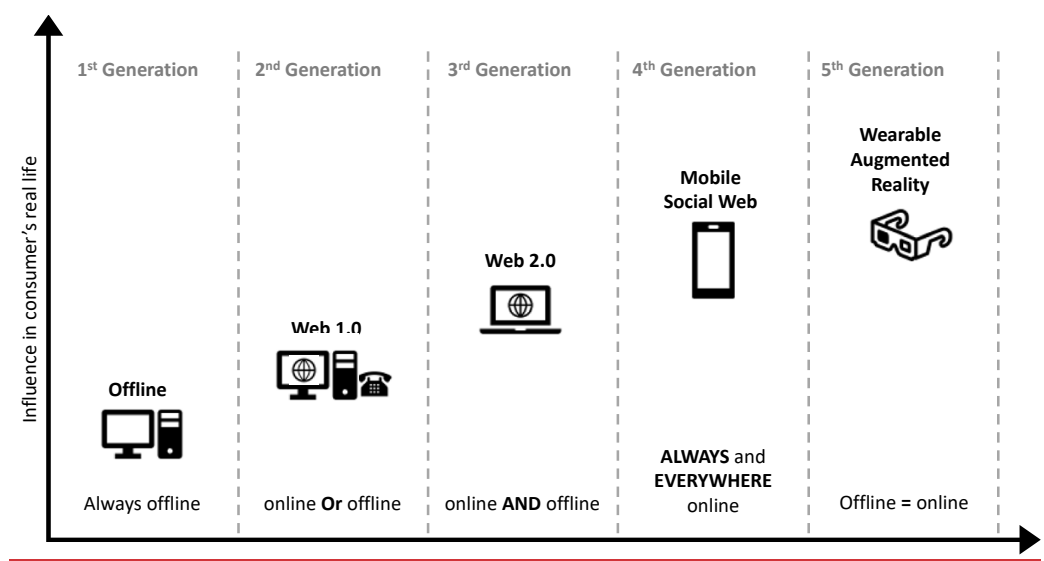

Fig. 1. Evolution of media devices

WARDs can be defined as "wearable technologies that merge virtual and physical realities". One example of these technologies is augmented reality glasses, which is the focus of this study. Augmented reality smart glasses (ARSGs) can be defined as wearable AR devices in the shape of regular glasses that merge virtual data with the physical environment in the user's field of view". Although WARDs have been around for a while, they have had a different adoption rate by users for different reasons. Some scholars attempted to understand users' acceptance of the use of new technology by developing several theories. The Technology Acceptance Model (TAM) is an information systems theory developed by Davis (1989) to predict users' acceptance and use of new technology. The TAM theory models users' acceptance and use of technology based on two primary factors: easy to use (perceived ease of use) and useful to use (perceived usefulness).

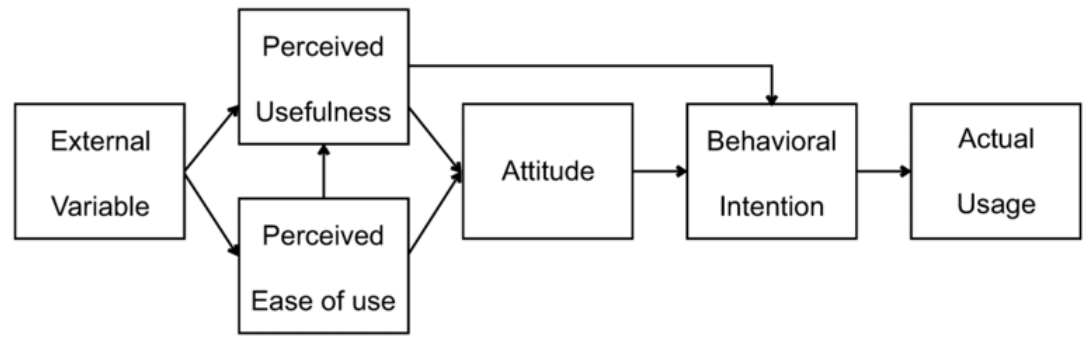

Fig. 2. TAM initial construct model

The TAM assumes that people are planning their behavior. The problem with this assumption is that people are not entirely rational in their behaviors and decisions. For example, the TAM does not explain why people line up to buy a new electronic device like a new iPhone before trying it out (Recker 2015), or why the latest gaming consoles such as PlayStation 5 are sold out before they become available in stores. The work of Venkatesh and Davis (2000) extended the TAM to the TAM2 (Fig. 2) to explain perceived usefulness and usage in terms of two components: social influences (job relevance, output quality, result demonstrability, and perceived ease of use) and cognitive instrumental processes (subjective norms, voluntariness, and image).

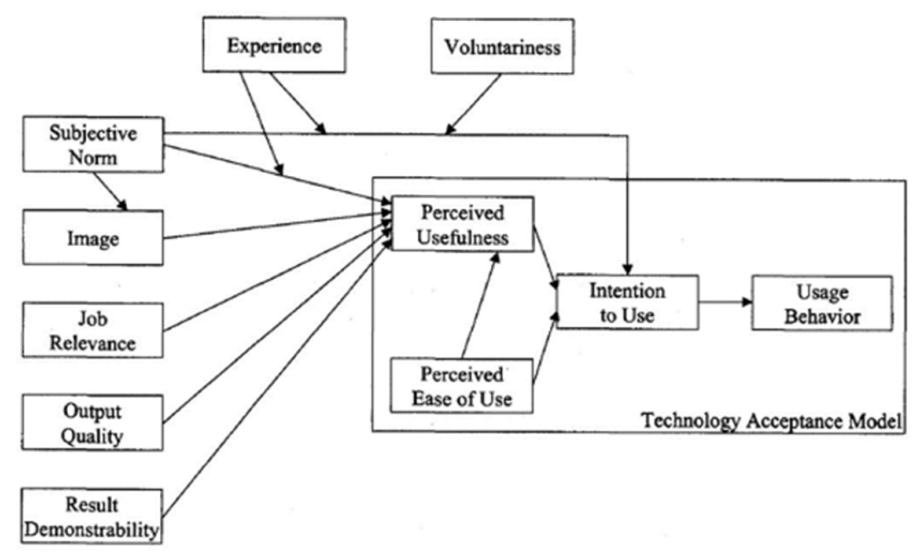

Fig. 3. TAM2 - Extension of the Technology Acceptance Model 
After the TAM 2, the information technology literature generated many competing models. Venkatesh et al. (2003) compared eight empirical models and their extensions. They formulated a unified model that integrates items across the eight models and validated them. They then proposed a new unified model called "The unified theory of acceptance and use of technology" (UTAUT). Venkatesh et al. (2003) added four main variables: 1) Performance Expectancy, 2) Effort Expectancy, 3) Social Influence, and 4) Facilitating Conditions. According to the UTAUT, the facilitation condition must be directly related to the actual behavior of the adopters, and not to the behavioral intentions. These four main concepts are independent variables that influence the dependent variables of behaviors and usage. In contrast, 1) gender, 2) age, 3) experience, and 4) voluntariness of use have an indirect effect on the dependent variables through the four main concepts. Behavioral intention is considered as a critical indicator of technology use.

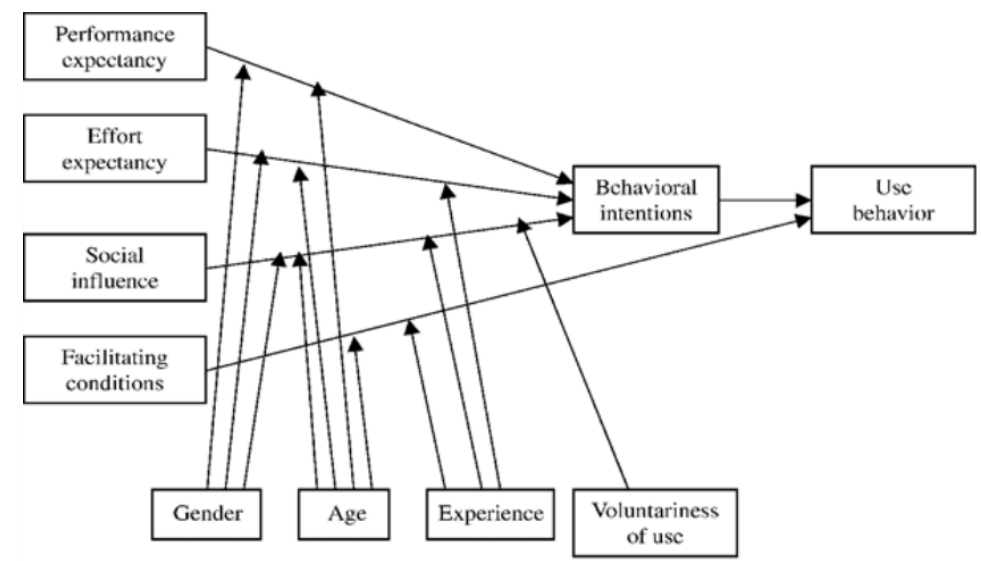

Fig. 4. Unified Theory of Acceptance and Use of Technology (UTAUT)

Nevertheless, previous models do not tell us how to make the technology easy to use or useful, nor does it give us any design advice on how to further improve it (Recker 2015). They did not address the role of interventions to aid managerial decisionmaking, nor how various interventions can impact implementing information technology solutions. Therefore, the work by Venkatesh and Bala (2008), included individual differences, system characteristics, social influences, and facilitating conditions (Rauschnabel \& Ro 2016).

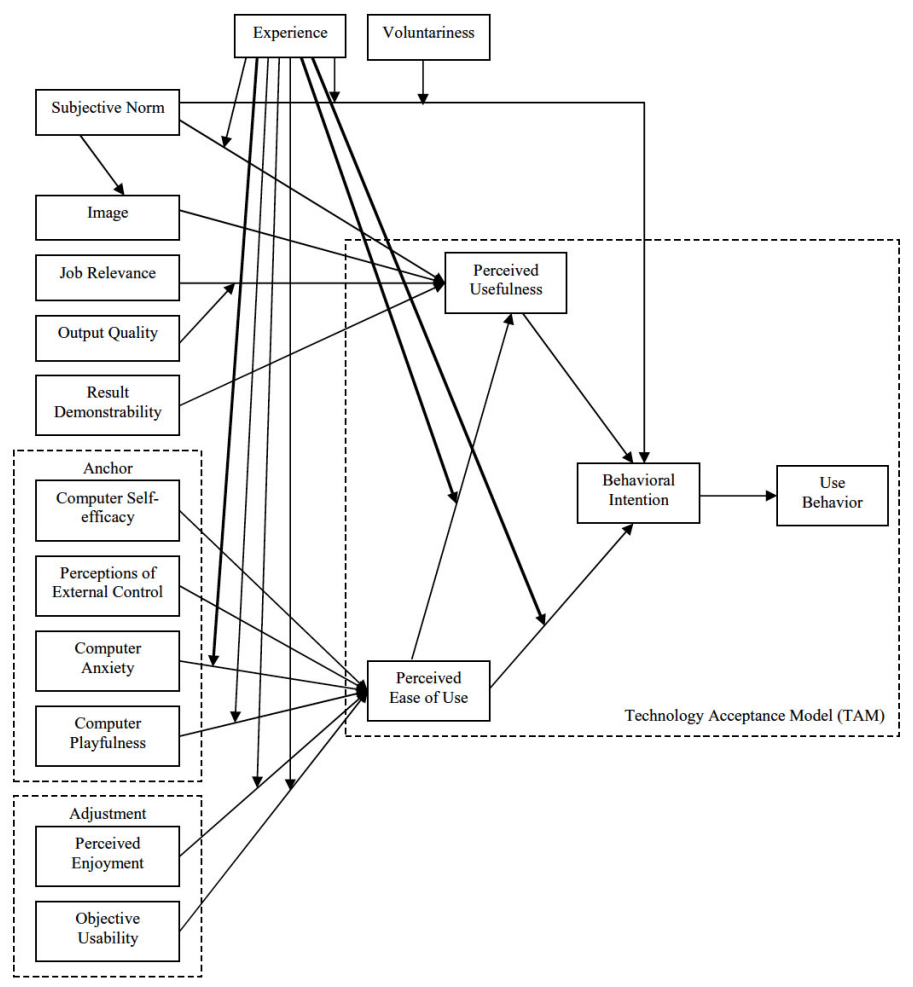

Fig. 5. Technology Acceptance Model TAM3 


\subsection{Overview of the related research}

Some scholars argue that technology acceptance model theories have not addressed the different contexts in which technologies might be used in. The work of Leue, Tom-Dieck and Jung (2014) concludes that the TAM needs to be revised for AR, and proposed an AR acceptance model that includes five external variables that might be included in future AR acceptance research: 1) Design and Identification, 2) User Friendliness, 3) Killer-Apps, 4) Price, and 5) Personal data. Similarly, Obeidy, Arshad and Huang (2017) discussed the lack of integrating dimensions that are specific to AR smart glasses and certain domains such as cultural tourism. They have also identified 1) information quality, 2) technology readiness, 3) visual appeal, and 4) facilitating conditions as external key variables influencing users' beliefs, attitudes, and usage intentions (Figure 6). Rauschnabel and Ro (2016) proposed an exploratory model of smart glasses adoption. Furthermore, they found out the importance of various factors on adopting ARSG, including functional benefits, ease of use, individual difference variables, brand attitudes, and social norms. On the other hand, self-presentation benefits and potential privacy concerns seem less likely to influence smart glasses adoption, even though smart glasses are similar to fashion accessories and capture various types of personal information.
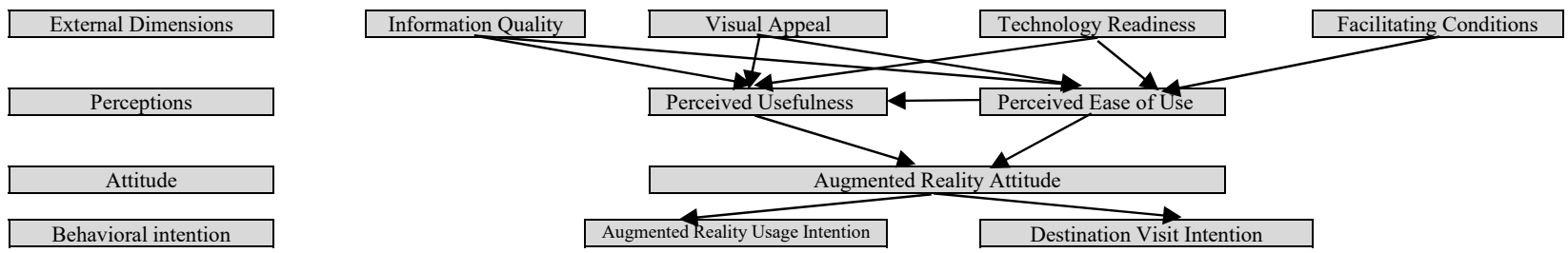

Fig. 6. An acceptance model for smart glasses

In contrast, Rauschnabel, He and Ro (2018) assess ARSG usage, and found out that ARSGs threat other's privacy, but not the user's privacy, which can highly impact adopting decisions. Moreover, expected usefulness, enjoyment, and symbolic benefits influence users' intention towards ARSGs.

\section{Research model and hypothesis development}

The following research model and hypotheses were developed to investigate the connections between the different social and technological factors that impact adopting ARSG. These include 1) basic knowledge, 2) social norms, 3) ease of use, 4) image, 5) usefulness, 6) brand attitude, 7) own privacy, 8) others' privacy, 9) multitasking, 10) technology innovativeness, and 11) enjoyment.

\subsection{Pre-Market Knowledge}

Existing knowledge about smart glasses refers to consumers' knowledge of smart glasses. Recent studies by Rauschnabel and Ro (2016) show that users' pre-existent knowledge or experience influences their decision to adopt a certain technology. This factor was added in this research as pre-market study, as the technology did not yet become available in the consumer market. Therefore, existing knowledge about the ARSG was added as a replacement for the existing experience. In the context of this study, it is believed pre-market knowledge about ARSG is more likely to have a critical role in predicting ARSG adoption. Therefore, the following hypothesis was presented:

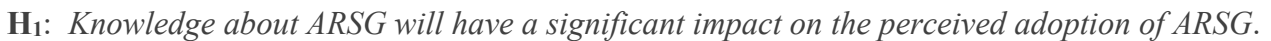

\subsection{Social norms}

Social norms can be defined as the degree to which users think that their important peers expect them to use a particular technology (Rauschnabel \& Ro 2016). When it comes to ARSG, it is believed that social norms may have a significant impact on the user adoption of ARSG devices. Therefore, the following hypothesis was presented:

\section{$\mathbf{H}_{2}$ : Social norms will have a significant impact on the perceived adoption of ARSG.}

\subsection{Ease of use}

Ease of use describes the degree to which users believe the technology of ARSG is easy to use. It was already highlighted in the proposed model by Davis (1989) as the perceived ease of use factor. The factor has been analyzed to determine how it impacts user decisions in adopting ARSG devices. The following hypothesis was stated:

$\mathbf{H}_{3}$ : Perceived ease of use will have a significant impact on the perceived adoption of ARSG. 


\subsection{Image}

Image can be defined as the level to which a user perceives that the use of technology will enhance his or her status in society (Venkatesh \& Bala 2008). Since ARSG can be used as regular glasses and as a fashionable accessory, it is believed that ARSG can also define a personal treat. The users may choose to adopt ARSG based on how strong ARSG will present their image. Thus, the following hypotheses were proposed:

H4: Image will have a significant impact on the perceived adoption of ARSG.

\subsection{Perceived usefulness}

Perceived usefulness refers to the level in which users think that using a certain technology would enhance their task performance (Davis 1989). In the context of ARSG, when looking at a physical environment such as a famous building, it can extract information about it and display it in the user's view or translate a book that a user is looking at to a preferred language (Rauschnabel, He \& Ro 2018). Hence, the following hypothesis was suggested:

\section{H5: Perceived usefulness will have a significant impact on the perceived adoption of ARSG.}

\subsection{Brand attitude}

Brand attitude refers to a buyer's overall assessment of a brand with regards to its perceived ability to satisfy a relevant motive (Percy \& Rossiter 1992). It is believed that the manufacturing brand of ARSG will also have some degree of influence on the adoption of this wearable technology. For example, if Apple glasses were introduced and users happen to be loyal to the brand, it might impact their decision to buy and use this technology. Therefore, the following hypothesis was presented:

$\mathbf{H}_{6}$ : Brand attitude will have a significant impact on the perceived adoption of ARSG.

\subsection{Privacy risk to one's own privacy}

User privacy can be defined as a user's right to determine when, how, and to what extent information about them is communicated to others (Kalloniatis, Kavakli \& Gritzalis 2008). Wearable technologies such as ARSG can pose a higher privacy risk for users because they are always on and online. Companies like Facebook and Google are often criticized for collecting too much personal information. If the consumer does not trust the company's brand, it might influence their decision to adopt this technology (Rauschnabel \& Ro 2016). Therefore, the following hypothesis was presented.

\section{$\mathbf{H}_{7}$ : Privacy will have a significant impact on the perceived adoption of ARSG.}

\subsection{Perceived risk to other people's privacy}

In regions like the Middle East, social norms and other's privacy are highly respected (Aburayya et al., 2020b). Since the nature of ARSG devices constantly scan the user's environment, people's privacy around the ARSG user could be violated. For example, there were cases when Google glass users were physically assaulted by non-users for violating their privacy (Russell 2014). It is human nature to avoid conflict with others, and if adopting this technology will put them at risk, it will undoubtedly influence their decision. Therefore, it is suggested to address this factor in the following hypothesis:

\section{$\mathbf{H}_{\mathbf{8}}$ : Perceived risk to other people's privacy will have a significant impact on the perceived adoption of ARSG.}

\subsection{Multitasking}

Initially, voice was the main feature of mobile phones, until they become smart phones with multitasking features such as a built-in camera, calendar, music player, etc. (Barkoczi \& Lobontiu 2016; Alghizzawi et al., 2018). Similarly, new apps and media features in ARSG might transform smart glasses to allow even more multitasking features that have not yet been used. Media multitasking can be referred as the practice of engaging in two or more media contents simultaneously, which requires significant cognitive effort and overlapping resources, compared to traditional media (Sun \& Zhong 2020). Multitasking might have a critical added value to adopt ARSG for those who require their hands to be free (drivers or carriers). Therefore, the following hypothesis was presented:

\section{H9: Multitasking will have a significant impact on the perceived adoption of ARSG.}

\subsection{Technology innovativeness}

Since not all consumers show the same tendency to adopt new technologies, some scholars suggest including innovations in the consumer, especially in analyzing products voluntarily adopted by consumers (Leue, Tom-Dieck \& Jung 2014; Capuyan et al., 2021). It is believed that users' willingness to be early adopters can influence embracing ARSG technologies. Thus, the following hypothesis was presented.

H10: Technology innovativeness in users will have a significant impact on the perceived adoption of ARSG. 


\subsection{Enjoyment}

Enjoyment refers to the degree to which using technology is perceived as fun in itself, regardless of any performance consequences that might be expected (Davis, Bagozzi \& Warshaw 1992). Previous studies indicated that perceived enjoyment influenced users to improve their user intention (Al-Emran et al. 2020; Ahmad et al., 2021). It is anticipated that ARSG will include elements of fun that will trigger users to adopt them. Therefore, the following hypothesis was suggested.

H11: Perceived Enjoyment will have a significant impact on the perceived adoption of ARSG.

Based on the above eleven hypotheses, a research model of social and technological factors as independent variables predicting the ARSG adoption as dependent variable was framed, which is presented in Fig. 7.

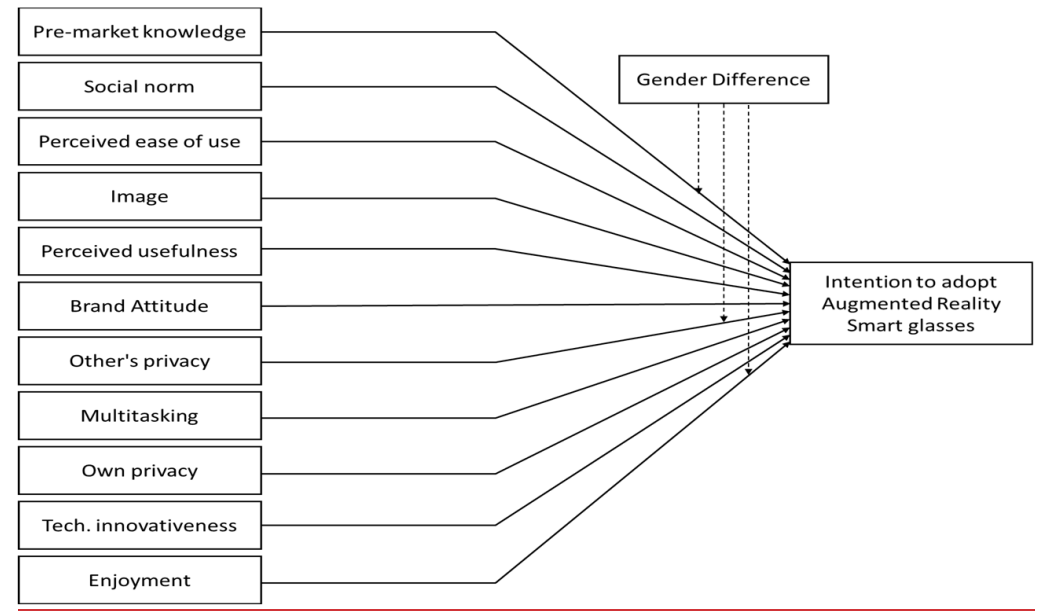

Fig. 7. Research Conceptual Framework

\section{Research Methodology}

\subsection{Context and subject}

The data was collected via an online survey using Google Forms. The target respondents were users living in the Middle East region. The link was shared via social mobile groups. The link was also shared via Instagram to maximize the response rate. Participation was voluntary. A total of 586 data points were collected. All results were mandatory. However, due to system error, two entries were eliminated due to missing educational values. Therefore, 584 completed data points were accepted for further analysis using SPSS. The collected sample size was sufficient and in line with the requirements stated by Krejcie and Morgan (1970).

Table 1

Participant demographics

\begin{tabular}{|c|c|c|c|}
\hline Measure & Items & Frequency & \\
\hline \multirow[t]{2}{*}{ Gender } & Male & 97 & 16.6 \\
\hline & Female & 485 & 83.3 \\
\hline \multirow[t]{6}{*}{ Age } & $13-17$ & 93 & 16.0 \\
\hline & $18-24$ & 189 & 32.5 \\
\hline & $25-34$ & 185 & 31.8 \\
\hline & $35-44$ & 99 & 17.0 \\
\hline & $45-54$ & 10 & 1.7 \\
\hline & $55-64$ & 6 & 1.0 \\
\hline \multirow[t]{5}{*}{ Education } & High school or less & 157 & 27.0 \\
\hline & Diploma & 37 & 6.4 \\
\hline & Bachelor & 300 & 51.5 \\
\hline & Master & 78 & 13.4 \\
\hline & Doctorate & 10 & 1.7 \\
\hline \multirow[t]{10}{*}{ Country } & KSA & 212 & 36.4 \\
\hline & UAE & 206 & 35.4 \\
\hline & Bahrain & 48 & 8.2 \\
\hline & Oman & 35 & 6.0 \\
\hline & Kuwait & 22 & 3.8 \\
\hline & Iraq & 12 & 2.1 \\
\hline & Qatar & 11 & 1.9 \\
\hline & Jordan & 9 & 1.5 \\
\hline & Egypt & 9 & 1.5 \\
\hline & Other & 18 & 3.1 \\
\hline
\end{tabular}




\subsection{Research instrument}

An online questionnaire was used to understand user intention to adopt ARSG. The first section contains questions specified to measure the construct in the research model using a seven-point Likert scale, with values ranging from "7 = strongly agree" to " 1 = strongly disagree". The second section included questions about the personal information of users. Questions 1-6 were adapted from Rauschnabel and Ro (2016), questions 7 and 8 from Rauschnabel, He and Ro (2018), question 9 from Sun and Zhong (2020), question 10 from Leue, Tom-Dieck and Jung (2014) and question 11 from Al-Emran et al. (2020). The sample description is provided in Table 1 .

Table 2

Reliability Statistics

\begin{tabular}{ccc}
\hline Cronbach's Alpha & Cronbach's Alpha Based on Standardized Items & Number of Items \\
\hline .825 & .792 & 14 \\
\hline
\end{tabular}

\subsection{Scale reliability and validity}

Cronbach's alpha was measured to validate the reliability of the data obtained. The results indicate a Cronbach's alpha value of $0.849 \%$, which ensures the instrument's stability. Table 2 indicates that most items correlate with each other, ranging from $\mathrm{r}=-0.302$ for image and perceived ease of use, to $\mathrm{r}=.640$ for adoption and technology innovativeness. Since the correlation values are relatively high among items, this would be a good candidate for factor analysis.

Table 3

Inter-Item Correlation

\begin{tabular}{|c|c|c|c|c|c|c|c|c|c|c|c|c|c|c|c|}
\hline & & 1 & 2 & 3 & 4 & 5 & 6 & 7 & 8 & 9 & 10 & 11 & 12 & 13 & 114 \\
\hline 1 & Pre-Market Knowledge & N/A & & & & & & & & & & & & & \\
\hline 2 & Social Norm & $.223^{* *}$ & N/A & & & & & & & & & & & & \\
\hline 3 & Ease of use & $.244^{* *}$ & $.285^{* *}$ & N/A & & & & & & & & & & & \\
\hline 4 & Image & $.310^{* *}$ & $.471^{* *}$ & $.302^{* *}$ & N/A & & & & & & & & & & \\
\hline 5 & Usefulness & $.197^{* *}$ & $.373^{* *}$ & $.480^{* *}$ & $.476^{* *}$ & N/A & & & & & & & & & \\
\hline 6 & Brand attitude & $.161^{* *}$ & $.378^{* *}$ & $.076^{*}$ & $.357^{* *}$ & $.204^{* *}$ & N/A & & & & & & & & \\
\hline 7 & Other's privacy & $.183^{* *}$ & $.157^{* *}$ & $.162^{* *}$ & $.319^{* *}$ & $.258^{* *}$ & $.214^{* *}$ & N/A & & & & & & & \\
\hline 8 & Multitasking & $.225^{* *}$ & $.256^{* *}$ & $.417^{* *}$ & $.386^{* *}$ & $.617^{* *}$ & $.186^{* *}$ & $.320^{* *}$ & N/A & & & & & & \\
\hline 9 & Own privacy & $.292^{* *}$ & $.291^{* *}$ & $.345^{* *}$ & $.403^{* *}$ & $.349^{* *}$ & $.280^{* *}$ & $.269^{* *}$ & $.397^{* *}$ & N/A & & & & & \\
\hline 10 & Enjoyment & $.236^{* *}$ & $.245^{* *}$ & $.428^{* *}$ & $.306^{* *}$ & $.476^{* *}$ & $.105^{* *}$ & $.175^{* *}$ & $.476^{* *}$ & $.329^{* *}$ & $\mathrm{~N} / \mathrm{A}$ & & & & \\
\hline 11 & Tech. Innovativeness & $.350^{* *}$ & $.291^{* *}$ & $.350^{* *}$ & $.354^{* *}$ & $.338^{* *}$ & $.245^{* *}$ & $.172^{* *}$ & $.357^{* *}$ & $.345^{* *}$ & $.350^{* *}$ & N/A & & & \\
\hline 12 & Adoption & $.394^{* *}$ & $.354^{* *}$ & $.406^{* *}$ & $.516^{* *}$ & $.450^{* *}$ & $.299^{* *}$ & $.305^{* *}$ & $.443^{* *}$ & $.498^{* *}$ & $.331^{* *}$ & $.640^{* *}$ & N/A & & \\
\hline 13 & Gender & $-.220^{* *}$ & $-.079^{*}$ & -.007 & -.054 & -.011 & -.044 & $-.117^{* *}$ & $-.074^{*}$ & -.021 & $-.070^{*}$ & $-.173^{* *}$ & $-.126^{* *}$ & N/A & \\
\hline 14 & Age & $-.075^{*}$ & .026 & $-.231^{* *}$ & -.002 & $-.112^{* *}$ & $.081^{*}$ & -.061 & $-.113^{* *}$ & $-.148^{* *}$ & $-.148^{* *}$ & -.038 & -.035 & $-.142^{* *}$ & N/A \\
\hline
\end{tabular}

\section{Results and discussion}

Fig. 8 presents the summary of the results.

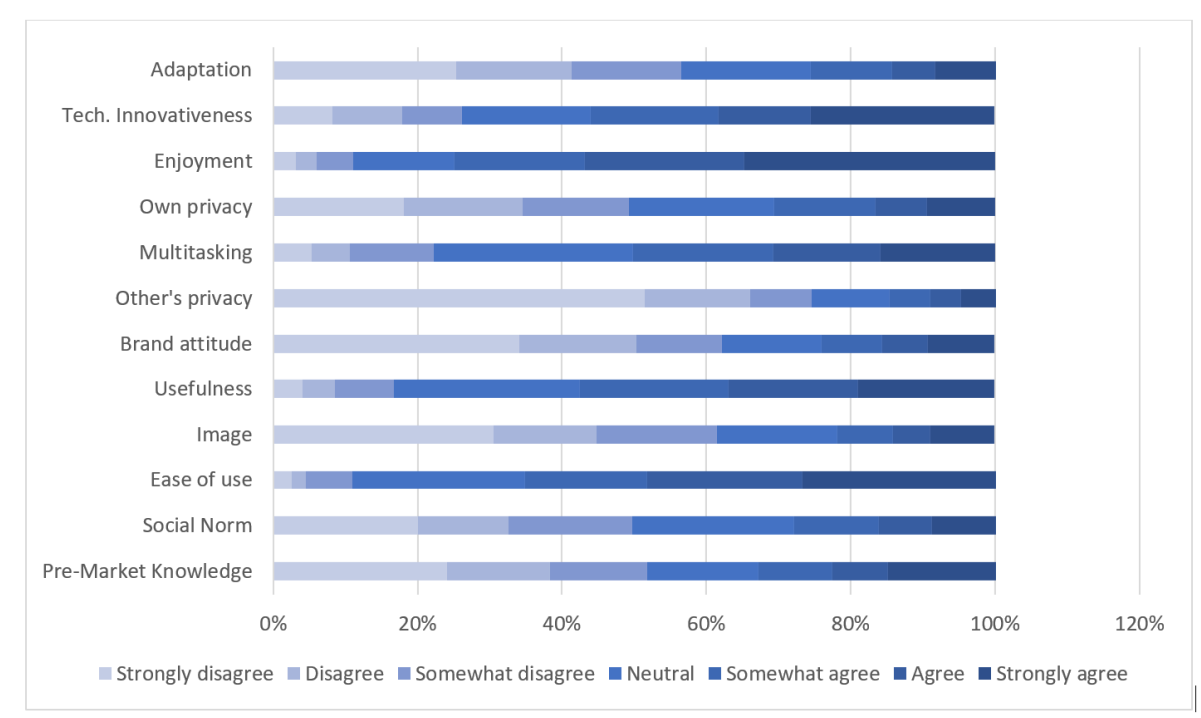

Fig. 8. User's perspective on the major factors data result 
The initial Likert scale results show a general agreement on factors like perceived ease of use, enjoyment, usefulness, and multitasking; and a general disagreement toward invading others' privacy. Figure 8 shows that the early adoption rate is notably low as one out of four are most likely to be among the early adopters of ARSG when they are released to the market. Nevertheless, the following analysis explains how these factors are related to adoption. The full Likert scale can be examined in the appendix in Table 7.

\subsection{What are the major factors that impact a user's decision to adopt ARSG?}

Pearson correlation coefficient was used to analyze the correlation between the quantitative variables. By analyzing the results in Table 4, it can be noticed that all factors had a positive relationship to the ARSG adoption factor with statistical significance. However, most of them are considered weak (below .5), except for technology innovativeness (.64), followed by self-presentation benefits image (.52). This shows that early adopters will be among the first to adopt ARSG. Moreover, the correlation between other's privacy and adoption intention is surprising, since users still show a positive correlation when asked if they trust the company to preserve their privacy. Besides, user privacy seems to have a minor impact, as it did not correlate negatively with user intention.

Table 4

Structural assessment results

\begin{tabular}{|c|c|c|c|c|}
\hline Hypothesis & Relationship & Correlation & P-value & Decision \\
\hline $\mathrm{H} 1$ & Pre-market knowledge $\rightarrow$ Adoption & .394 & $<.001$ & Supported \\
\hline H2 & Social norm $\rightarrow$ Adoption & .354 & $<.001$ & Supported \\
\hline H3 & Ease of use $\rightarrow$ Adoption & .406 & $<.001$ & Supported \\
\hline H4 & Image $\rightarrow$ Adoption & .516 & $<.001$ & Supported \\
\hline H5 & Usefulness $\rightarrow$ Adoption & .450 & $<.001$ & Supported \\
\hline H6 & Brand attitude $\rightarrow$ Adoption & .299 & $<.001$ & Supported \\
\hline H7 & Other's privacy $\rightarrow$ Adoption & .305 & $<.001$ & Supported \\
\hline H8 & Own privacy $\rightarrow$ Adoption & .498 & $<.001$ & Supported \\
\hline H9 & Multitasking $\rightarrow$ Adoption & .443 & $<.001$ & Supported \\
\hline H10 & Tech. innovativeness $\rightarrow$ Adoption & .640 & $<.001$ & Supported \\
\hline H11 & Enjoyment $\rightarrow$ Adoption & .331 & $<.001$ & Supported \\
\hline
\end{tabular}

This indicates that worrying about the user's or about others' privacy does not have a significant impact on ARSG, even in conservative regions such as the Middle East. These results are partially in line with the findings by Rauschnabel, He and Ro (2018), who did not show any significant effects for the risk of threatening own privacy, and found a weak significant negative effect for the risk of threatening other people's privacy $(\beta \mathrm{H} 5=-0.169, \mathrm{p}<.05)$.

\subsection{Hypotheses testing}

This section aims to test the hypothesized theoretical model which consists of eleven main hypotheses formulated by the researchers in this study. These eleven main hypotheses are related to the individual effect of the eleven social and technological factors which are independent variables on the ARSG adoption as dependent variable. In this study, the hypothesized theoretical model consists of 11 social and technological factors and one ARSG adoption factor and has 11 hypotheses that will be tested simultaneously by employing Multiple Regression Analysis (MRA) using SPSS. The 11 social and technological factors are treated as directly observed variables, which are independent variables. The values of each factor can be calculated by summing the scores of each item in that factor. X1, X2, X3, X4, X5, X6, X7, X8, X9, X10 and X11 are used to represent the 11 independent variables. On the other hand, there is one dependent variable that is ARSG adoption. The results of the MAR that 11 social and technological independent variables predicting the one ARSG adoption dependent variable are displayed in Table 5.

\section{Table 5}

Multiple Regression Analysis of Social \& Technological Factors with ARSG adoption

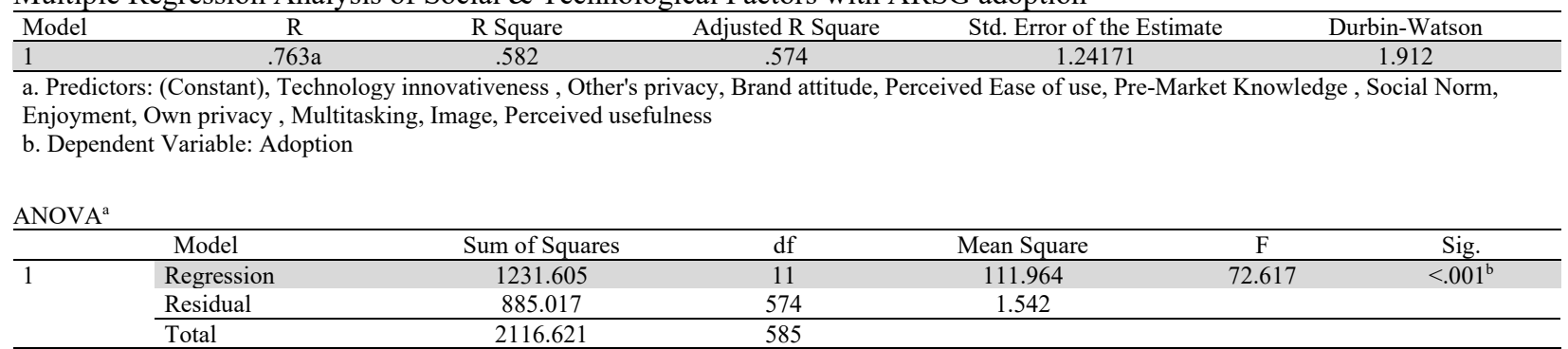

a. Dependent Variable: Adoption

b. Predictors: (Constant), Technology innovativeness, Other's privacy, Brand attitude, Perceived Ease of use, Pre-Market Knowledge, Social Norm, Enjoyment, Own privacy, Multitasking, Image, Perceived usefulness 
Coefficients $^{\mathrm{a}}$

\begin{tabular}{|c|c|c|c|c|c|c|c|c|}
\hline \multirow{2}{*}{\multicolumn{2}{|c|}{ Model }} & \multirow{2}{*}{$\begin{array}{c}\text { Unstandardized } \\
\text { B }\end{array}$} & \multirow{2}{*}{$\begin{array}{l}\text { Coefficients } \\
\text { Std. Error }\end{array}$} & \multirow{2}{*}{$\begin{array}{c}\text { Standardized } \\
\text { Coefficients } \\
\text { Beta }\end{array}$} & \multirow{2}{*}{$\mathrm{t}$} & \multirow{2}{*}{ Sig. } & \multicolumn{2}{|c|}{ Collinearity Statistics } \\
\hline & & & & & & & Tolerance & VIF \\
\hline \multirow[t]{12}{*}{1} & (Constant) & -1.241 & .231 & & -5.381 & $<.001$ & & \\
\hline & Pre-Market Knowledge & .084 & .027 & .093 & 3.111 & .002 & .809 & 1.236 \\
\hline & Social Norm & .012 & .033 & .011 & .351 & .725 & .682 & 1.467 \\
\hline & Perceived Ease of use & .092 & .041 & .074 & 2.220 & .027 & .662 & 1.512 \\
\hline & Image & .167 & .035 & .169 & 4.786 & .002 & .584 & 1.712 \\
\hline & Perceived usefulness & .095 & .046 & .080 & 2.064 & .039 & .484 & 2.064 \\
\hline & Brand attitude & .027 & .029 & .028 & .913 & .361 & .772 & 1.295 \\
\hline & Other's privacy & .072 & .031 & .068 & 2.301 & .022 & .830 & 1.205 \\
\hline & Multitasking & .069 & .043 & .060 & 1.598 & .110 & .524 & 1.909 \\
\hline & Own privacy & .177 & .033 & .174 & 5.367 & .001 & .693 & 1.443 \\
\hline & Technology innovativeness & .406 & .032 & .413 & 12.881 & .000 & .708 & 1.412 \\
\hline & Enjoyment & -.072 & .040 & -.060 & -1.813 & .070 & .660 & 1.514 \\
\hline
\end{tabular}

Dependent Variable: Adoption

Table 5 shows that the regression model demonstrates a robust fitness at R-value of 0.763 and R-squared of 0.582 , which indicates that $58.2 \%$ of the variation in ARSG adoption explained by the eleven social and technological factors. The ANOVA table shows an F-statistic $=72.617$ (p-value $<.001$ ) indicating that the multiple regression model with independent variables of 11 social and technological factors is significant at $1 \%$ level in predicting the variability of ARSG adoption. Thus, the regression model is a good fit of the data. Table 5 shows the Beta coefficient of each independent variable and its significant level. The table above indicates that four of the independent variables including Pre-Market Knowledge, Image, Own privacy and Technology innovativeness show the significant effect on ARSG adoption at the 1\% significant level. In addition, Table 5 indicates that three of the social and technological factors include Perceived Ease of use, Perceived usefulness and Other's privacy show the significant effect on ARSG adoption at the 5\% significant level. Among the 7 social and technological factors, technological innovativeness expresses the strongest effect on ARSG adoption with highest coefficient value of 0.413 $(\mathrm{b}=0.413, \mathrm{t}=12.881, \rho<0.01)$. Own privacy, image, pre-market Knowledge, Perceived usefulness, perceived ease of use and Other's privacy represent the relative smaller effects with coefficient values of $(b=0.174, t=5.367, \rho<0.01) ;(b=0.169$, $\mathrm{t}=4.786, \rho<0.01) ;(\mathrm{b}=0.093, \mathrm{t}=3.111, \rho<0.01) ;(\mathrm{b}=0.080, \mathrm{t}=2.064, \rho<0.05) ;(\mathrm{b}=0.074, \mathrm{t}=2.220, \rho<0.05) ;(b=0.068$, $\mathrm{t}=2.301, \rho<0.05)$, respectively. Social norm, brand attitude, multitasking and enjoyment factors, however, are the only independent variables which do not indicate the significant effect on ARSG adoption at the 5\% level. Accordingly, the result of model analysis concluded that H1, H3, H4, H5, H7, H9 and $\mathrm{H} 10$ are accepted. Thus, pre-market knowledge, image, own privacy, technology innovativeness, perceived ease of use, perceived usefulness and Other's privacy have significant positive effects on ARSG adoption Results of testing the developed theoretical model in this study can be seen in Fig. 9.

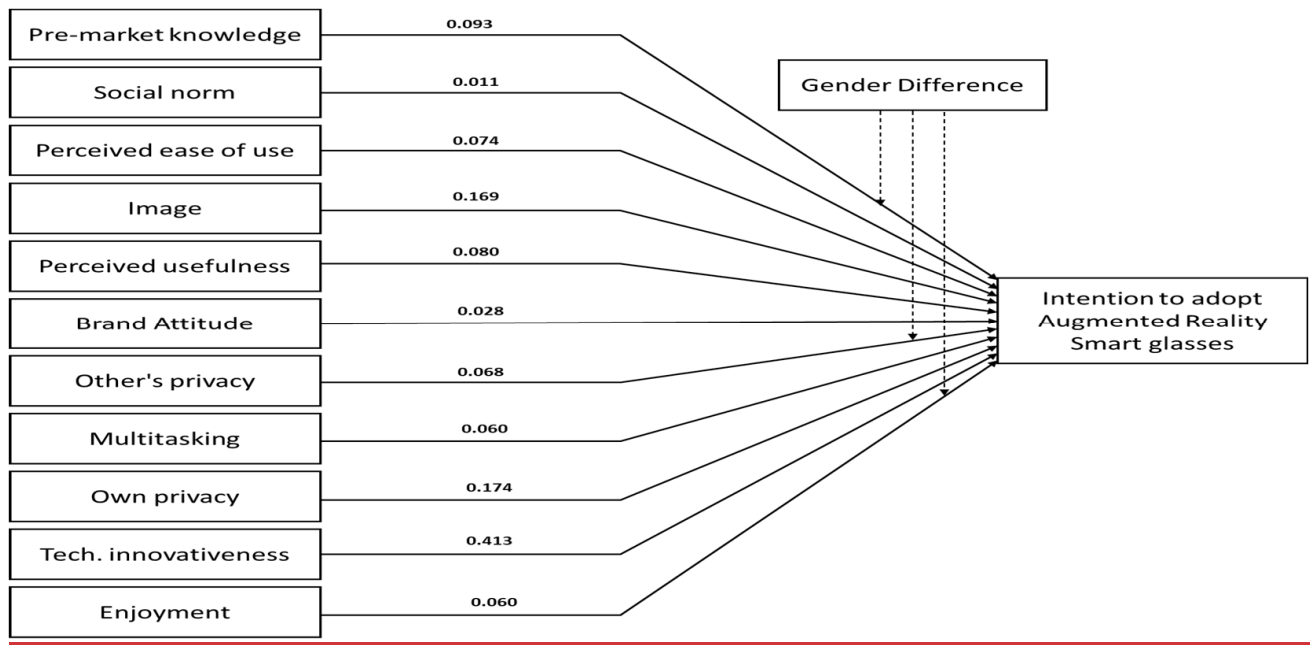

Fig. 9. Results of Testing Study theoretical model

\subsection{Is There a significant difference between male and female intention to adopt ARSG?}

To identify if gender has a significant difference in adopting intention towards ARSG, we analyzed the median of each gender. By observing the chart in Figure 10, we notice that there is a difference in the median between males (who expressed neutral intention) (4) toward ARSG adoption than females (3). The significance level was tested using a two-sample t-test, assuming equal variances were conducted, showing that we can notice that the P-value $=0.002$, which is less than the value of $\alpha=0.05$, indicating a significant difference. 


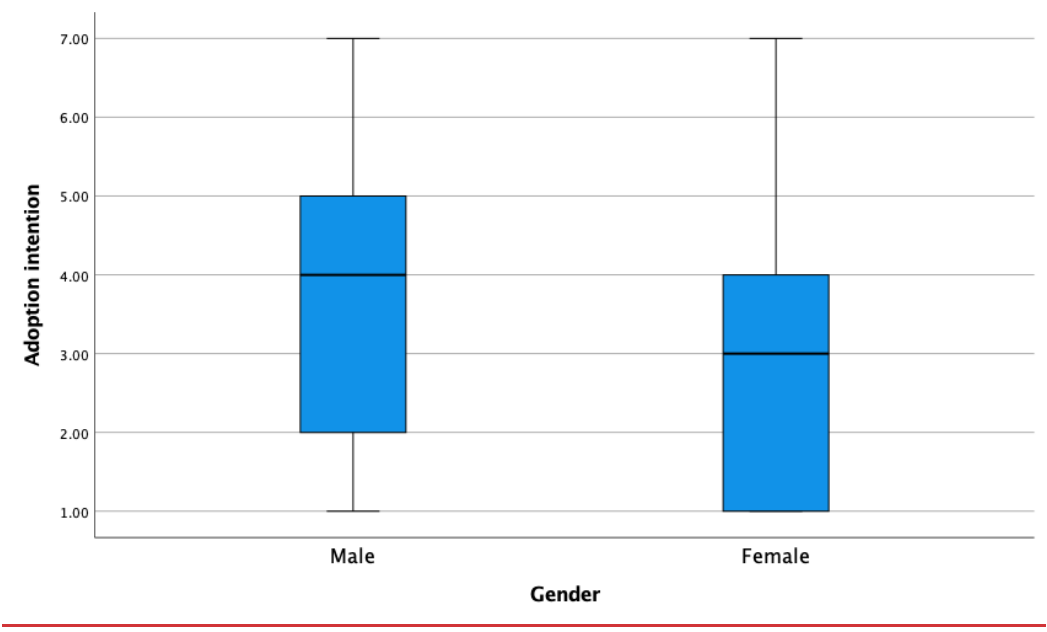

Fig. 10. Adoption intention by gender

Moreover, Table 5 also shows that males are more likely to be early adopters than females, as technology innovativeness for males is significantly higher. Besides, there is also a significant difference in pre-market knowledge between males and females, suggesting that males are more familiar with ARSG technologies than females. In contrast, females do care more about others' privacy, as the analyzed data shows a significant difference between males and females, where females are less likely to adopt ARSG if it violates others' privacy.

Table 5

Factor analysis by gender

\begin{tabular}{|c|c|c|c|c|c|}
\hline & \multicolumn{2}{|c|}{ Overall sample } & \multicolumn{3}{|c|}{ Gender } \\
\hline & Mean & $\mathrm{SD}$ & $\mathrm{F}$ & M & $\mathrm{P}$ \\
\hline Pre-Market Knowledge & 3.56 & 2.11 & 3.35 & 4.60 & $<.001$ \\
\hline Social Norm & 3.50 & 1.86 & 3.43 & 3.82 & 0.06 \\
\hline Ease of use & 5.23 & 1.53 & 5.22 & 5.25 & 0.88 \\
\hline Image & 3.07 & 1.93 & 3.03 & 3.31 & 0.19 \\
\hline Usefulness & 4.84 & 1.60 & 4.83 & 4.88 & 0.79 \\
\hline Brand attitude & 3.01 & 2.01 & 2.97 & 3.21 & 0.29 \\
\hline Other's privacy & 2.36 & 1.81 & 2.27 & 2.84 & 0.01 \\
\hline Multitasking & 4.58 & 1.64 & 4.53 & 4.86 & 0.07 \\
\hline Own privacy & 3.54 & 1.87 & 3.53 & 3.63 & 0.62 \\
\hline Enjoyment & 5.46 & 1.58 & 5.41 & 5.71 & 0.09 \\
\hline Tech. Innovativeness & 4.67 & 1.94 & 4.52 & 5.42 & $<.001$ \\
\hline Adoption & 3.25 & 1.90 & 3.14 & 3.78 & 0.00 \\
\hline
\end{tabular}

5.4 Is there a significant difference in education and age among the people who intend to use ARSG?

Education and age have little to no impact on ARSG Adoption. By observing Fig. 11, it can be noticed that the median $=3$ (somewhat disagree) across all education levels. Although the figure shows that the doctorate level has slightly less intention to adopt ARSG, this difference is insignificant, as $\mathrm{P}=.28$ exceeds the value of $\alpha=0.05$. The same conclusion can be mentioned about age, as $\mathrm{P}=.10$, indicating that age has no significant impact on the user's intention to adopt ARSG. 


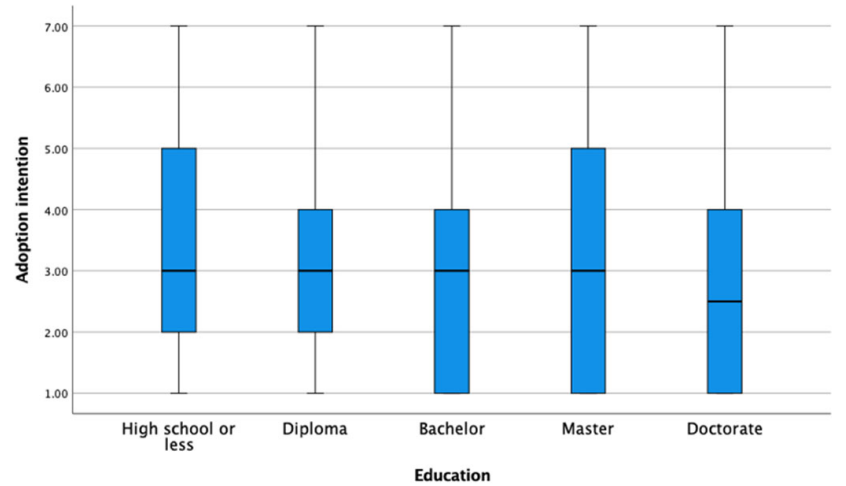

Fig. 11. ARSG adoption by level of education

\subsection{Is there a significant difference in country among the people who will most like intend to use ARSG?}

ARSG adoption is significantly different by country. Fig. 12 shows how people from different countries intend to adopt ARSG. The result indicates a significant difference, with a $p=.002$, being less than the value of $\alpha=0.05$. This shows that some countries have a higher adoption rate of ARSG technologies compared to others such as the UAE (n=206) and Oman $(\mathrm{n}=35)$.

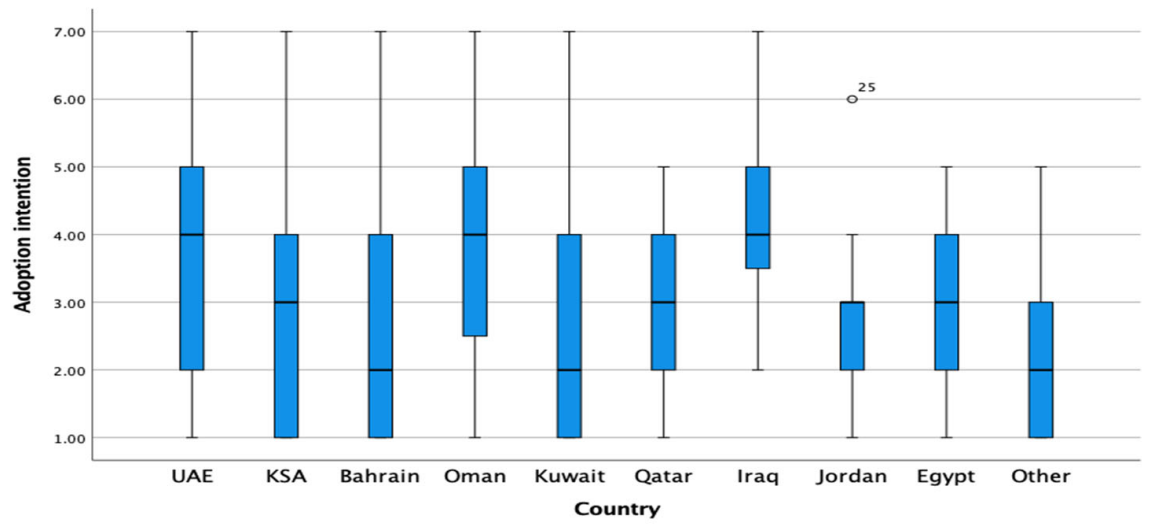

Figure 12 ARSG Adoption intention by country

\subsection{What are the possible numbers and characteristics of user clusters who will most likely adopt the ARSG?}

There are several statistical methods used to identify the possible number and characteristics of user clusters. Exploratory factor analysis (EFA) was conducted to determine the factors within these data that define certain personas. First, Bartlett's Sphericity and Kaiser-Meyer-Olkin (KMO) tests were conducted. The results show that KMO = .87 and Bartlett's test of Sphericity was statistically significant at the $\mathrm{p}<0.001$ level. EFA was performed using the Varimax rotation method using loading factors greater than 0.4 , combined with eigenvalues greater than 1.0. EFA generated two components with $74.14 \%$ of the total variance. Table 5 shows the two components with the associated factors for each. Component 1 is associated with enjoyment, multitasking, perceived ease of use, and usefulness. These factors can be clustered to build up a "Persona". A persona refers to a representation of the need and behavior of a hypothesized group of users (Humphrey 2017; Habes et al., 2019). The first clusters of factors can be connected to build a persona of type A, where this specific side of ARSG might appeal to them. On the other hand, the second component is associated with brand attitude, image, social norms, adoption intention, own privacy, others' privacy, and tech. The aspects of innovativeness, and pre-market knowledge, might appeal to a persona of type B. For example, smart glasses from Google might appeal to the type A persona, who have different priorities (usefulness, enjoyment and multitasking) than the Type B persona. In comparison, smart glasses from Apple might appeal more to people with a type B persona, who prioritize other factors such as brand, attitude, image, and social norms. These findings can significantly enhance the marketing positioning of the ARSG devices when they are ready to launch and market.

Table 6

Exploratory Factor Analysis Results

\begin{tabular}{lcc}
\hline & Persona A & Persona B \\
\hline Enjoyment & .746 & \\
Multitasking & .733 & \\
\hline
\end{tabular}




\begin{tabular}{lr}
\hline Perceived Ease of use & .730 \\
Perceived usefulness & .724 \\
Brand attitude & .762 \\
Image & .684 \\
Social Norm & .643 \\
Adoption intention & .627 \\
Own privacy & .512 \\
Tech. innovativeness & .491 \\
Pre-Market Knowledge & .452 \\
Other's privacy & .429 \\
\hline
\end{tabular}

\section{Conclusion}

This study investigated user behavior and intention toward ARSG in the Middle East. The findings show a significant positive link between all the tested variables and adoption intention. The findings suggest that early adopters and image as perceived self-presentation to be among the most substantial leading factors toward adopting ARSG. The results also indicate that males are more open to trying the ARSG first. Education and age showed no significant impact on users' decisions. However, the adoption intention varies significantly between countries, suggesting that countries like the UAE and Oman could potentially be the first countries in the Middle East to adopt ARSG technologies once debuted.

\subsection{Limitations}

Due to time limitations, the survey was not sent to technology and market experts for evaluation. Experts will have a useful role in evaluating the relevance of items under each factor, and make sure that the language is clear enough for the respondents. Based on the suggestions of experts, it was possible to improve the quality of the questionnaire. Moreover, using online surveys in social media might have younger adults, females or technology-oriented customers overrepresented. Future research can use other forms and channels to reach a more diverse audience. Moreover, to keep the questionnaire shorter, each factor was tested using one question only, as adding more questions might lead to less likely participation and less data collected. Future work uses additional questions associated with each factor to further improve overall reliability.

\section{Acknowledgment}

This study could not be possible without the guidance of Professor Dr Sa'Ed M. Salhieh. It is a part of a project done in the British University in Dubai. The authors declare no conflict of interest.

\section{References}

Aburayya, A., Alshurideh, M., Al Marzouqi, A., Al Diabat, O., Alfarsi, A., Suson, R., Salloum, S. A., Alawadhi, D. \& Alzarouni, A. (2020a). Critical Success Factors Affecting the Implementation of TQM in Public Hospitals: A Case Study in UAE Hospitals. Systematic Reviews in Pharmacy, 11(10), 230-242.

Aburayya, Ahmad, Alshurideh, M., Al Marzouqi, A., Al Diabat, O., Alfarsi, A., Suson, R., ... Salloum, S. A. (2020b). An Empirical Examination of the Effect of TQM Practices on Hospital Service Quality: An Assessment Study in UAE Hospitals. Systematic Reviews in Pharmacy, 11(9), 347-362.

Ahmad, A., Alshurideh, M., Al Kurdi, B., Aburayya, A. \& Hamadneh, S. (2021). Digital transformation metrics: a conceptual view. Journal of management Information and Decision Sciences, 24(7), 1-18.

Al Kurdi, B., Alshurideh, M., \& Salloum, S. A. (2020). Investigating a theoretical framework for e-learning technology acceptance. International Journal of Electrical and Computer Engineering (IJECE), 10(6), 6484-6496.

Al Kurdi, B., Alsurideh, M., Nuseir, M., Aburayya, A. \& Salloum, S.A. (2021). The effects of subjective norm on the intention to use social media networks: An exploratory study using PLS-SME and machine learning approach. In A. Hassanien \& K. Chang. Advanced Machine Learning Technologies and Applications, 324-334. Springer.

Alaali, N., Al Marzouqi, A., Albaqaeen, A., Dahabreh, F., Alshurideh, M., Mouzaek, E., Alrwashdh, S., Iyadeh, I., Salloum, S. \& Aburayya, A. (2021). The Impact of Adopting Corporate Governance Strategic Performance in the Tourism Sector: A Case Sudy in the kingdom of Bahrain. Journal of Legal, Ethical and Regulatory Issues, 24(1), 1-18.

Albrecht, U., von Jan, U., Kuebler, J., Zoeller, C., Lacher, M., Muensterer, O. J., Ettinger, M., Klintschar, M. \& Hagemeier, L. (2014). Google Glass for documentation of findings: evaluation in forensic medicine. Journal of medical Internet research, 16(2), p. e53.

Al-Emran, M., Al-Maroof, R., Al-Sharafi, M. A. \& Arpaci, I. (2020). What impacts learning with wearables? An integrated theoretical model. Interactive Learning Environments. Routledge.

Alghizzawi, M., Ghani, M. A., Som, A. P. M., Ahmad, M. F., Amin, A., Bakar, N. A., ... Habes, M. (2018). The Impact of Smartphone Adoption on Marketing Therapeutic Tourist Sites in Jordan. International Journal of Engineering \& Technology, 7(4.34), 91-96.

Al-Khayyal, A., Alshurideh, M., Al Kurdi, B. \& Aburayya, A. (2020). The impact of electronic service quality dimensions on customers' e-shopping and e-loyalty via the impact of e-satisfaction and e-trust: A qualitative approach. International Journal of Innovation, Creativity and Change, 14(9), 257-281. 
Al-Maroof, R. S., Alhumaid, K., Alhamad, A. Q., Aburayya, A. \& Salloum, S. (2021a). User acceptance of smart watch for medical purposes: an empirical study. Future Internet, 13(5), 127.

Al-Maroof, R., Ayoubi, K., Alhumaid, K., Aburayya, A., Alshurideh, M., Alfaisal, R. \& Salloum, S. (2021b). The acceptance of social media video for knowledge acquisition, sharing and application: A com-parative study among YouTube users and TikTok Users' for medical purposes. International Journal of Data and Network Science, 5(3), 197-214.

Alshurideh, M. (2018). Pharmaceutical Promotion Tools Effect on Physician's Adoption of Medicine Prescribing: Evidence from Jordan. Modern Applied Science, 12(11).

Alshurideh, M., Al Kurdi, B. \& Salloum S.A. (2020). Examining the Main Mobile Learning System Drivers' Effects: A Mix Empirical Examination of Both the Expectation-Confirmation Model (ECM) and the Technology Acceptance Model (TAM). In: Hassanien A., Shaalan K., Tolba M. (eds) Proceedings of the International Conference on Advanced Intelligent Systems and Informatics 2019. AISI 2019. Advances in Intelligent Systems and Computing, vol 1058. Springer, Cham. https://doi.org/10.1007/978-3-030-31129-2_37.

AlSuwaidi, S. R., Alshurideh, M., Al Kurdi, B. \& Aburayya, A. (2021). The Main Catalysts for Collaborative R\&D Projects in Dubai Industrial Sector. In The International Conference on Artificial Intelligence and Computer Vision (pp. 795-806). Springer.

Barkoczi, N. \& Lobontiu, G. (2016). Theoretical aspects of the acceptance of new technologies on the smartphone market. Innovative Ideas in Science. IOP Conference Series: Materials Science and Engineering, pp. 200-012060.

Capuyan, D. L., Capuno, R. G., Suson, R., Malabago, N. K., Ermac, E. A., Demetrio, R. A. M., ... Medio, G. J. (2021). Adaptation of innovative edge banding trimmer for technology instruction: A university case. World Journal on Educational Technology: Current Issues, 13(1), 31-41.

Davis, F. D. (1989). Perceived Usefulness, Perceived Ease Of Use, And User Accep. MIS Quarterly, vol. 13(3), pp. 319-340.

Davis, F. D., Bagozzi, R. P. \& Warshaw, P. R. (1992). Extrinsic and Intrinsic Motivation to Use Computers in the Workplace. Journal of Applied Social Psychology, 22(14), pp. 1111-1132.

Elmqaddem, N. (2019). Augmented Reality and Virtual Reality in Education. Myth or Reality? iJET, 14(3), pp. $234-242$.

Habes, M., Salloum, S. A., Alghizzawi, M., \& Mhamdi, C. (2020). The Relation Between Social Media and Students' Academic Performance in Jordan: YouTube Perspective. Advances in Intelligent Systems and Computing (Vol. 1058). https://doi.org/10.1007/978-3-030-31129-2 35.

Hamadneh, S., Hassan, J., Alshurideh, M., Al Kurdi, B., \& Aburayya, A. (2021). The effect of brand personality on consumer self-identity: the moderation effect of cultural orientations among British and Chinese consumers. Journal of Legal, Ethical and Regulatory, 24( Special Issue-1), 1-14.

Haselton, T. (2019). Apple glasses said to launch in 2023. CNBC.

Healey, K. \& Stephens, N. (2017). Augmenting justice: Google glass, body cameras, and the politics of wearable technology. Journal of Information, Communication and Ethics in Society. Emerald Group Holdings Ltd., 15(4), $370-384$.

Heath, A. (2017). Fewer Than Half Snapchat Spectacles Owners Used Glasses After 1 Month. Insider.

Heath, A. (2021). Snap's new Spectacles let you see the world in augmented reality - The Verge. The Verge.

Humphrey, A. (2017). User Personas and Social Media Profiles. Persona Studies. Deakin University, 3(2), p. 13.

Kalloniatis, C., Kavakli, E. \& Gritzalis, S. (2008). Addressing privacy requirements in system design: The PriS method. Requirements Engineering. Springer, 13(3), 241-255.

Khor, W. S., Baker, B., Amin, K., Chan, A., Patel, K. \& Wong, J. (2016). Augmented and virtual reality in surgery-the digital surgical environment: Applications, limitations and legal pitfalls. Annals of Translational Medicine. AME Publishing Company, 4(23).

Kothari, J. (2019). Glass Enterprise Edition 2: faster and more helpful. Google| The Keyword.

Krejcie, R. V. \& Morgan, D. W. (1970). Determining Sample Size for Research Activities. Educational and Psychological Measurement. SAGE Publications, 30(3), pp. 607-610.

Leue, M. C., Tom-Dieck, D. \& Jung, T. (2014). A Theoretical Model of Augmented Reality Acceptance. E-review of Tourism Research, 5 .

Mouzaek, E., Al Marzouqi, A., Alaali, N., Salloum, S. A., Aburayya, A. \& Suson, R. (2021). An Empirical Investigation of the Impact of Service Quality Dimensions on Guests Satisfaction: A Case Study of Dubai Hotels. Journal of Contemporary Issues in Business and Government, 27(3), 1186-1199.

Novet, J. (2021). Microsoft wins contract to make modified HoloLens for U.S. Army. CNBC.

Obeidy, W. K., Arshad, H. \& Huang, J. Y. (2017). An acceptance model for smart glasses based tourism augmented reality. AIP Conference Proceedings. American Institute of Physics Inc., p. 20080.

Percy, L. \& Rossiter, J. R. (1992). A model of brand awareness and brand attitude advertising strategies. Psychology \& Marketing, 9(4), pp. 263-274.

Phelan, D. (2020). Apple AR Glasses: Insider Leaks Price, Camera \& Design Details, Report Claims. Forbes.

Rauschnabel, P. A. \& Ro, Y. K. (2016). Augmented reality smart glasses: an investigation of technology acceptance drivers. International Journal of Technology Marketing. Inderscience Publishers, 11(2), p. 123.

Rauschnabel, P. A., Brem, A. \& Ro, Y. K. (2015). Augmented Reality Smart Glasses: Definition, Conceptual Insights, and Managerial Importance. Unpublished Working Paper, The University of Michigan-Dearborn, College of Business.

Rauschnabel, P. A., He, J. \& Ro, Y. K. (2018). Antecedents to the adoption of augmented reality smart glasses: A closer look at privacy risks. Journal of Business Research, 92, 374-384.

Recker, J. (2015). Technology Acceptance Model. Queensland University of Technology. 
Russell, K. (2014). I Was Assaulted for Wearing Google Glass. Insider.

Salloum, S. A., Al-Emran, M., Abdallah, S., \& Shaalan, K. (2017). Analyzing the Arab Gulf Newspapers Using Text Mining Techniques. In International Conference on Advanced Intelligent Systems and Informatics (pp. 396-405). Springer. https://doi.org/10.1007/978-3-319-64861-3_37.

Salloum, S.A., Al Ahbabi, N., Habes, M., Aburayya, A. \& Akour, I. (2021). Predicting the intention to use social media sites: A hybrid SME- machine learning approach. In A. Hassanien \& K. Chang (Eds.), Advanced Machine Learning Technologies and Applications, 324-334.

Shahin, I., Bou Nassif, A., Elnagar, A. Gamal, S., Salloum, S,A., \& Aburayya, A. (2021). Neurofeedback interventions for speech and language impairment: a systematic review. Journal of Management Information and Decision Sciences, 24 (Special Issue-1), 1-30.

StoryHub. (2021). Lenovo Introduces the ThinkReality A3 - The Most Versatile Smart Glasses Ever Designed for the Enterprise | Lenovo StoryHub. Lenovo.

Sun, T. \& Zhong, B. (2020). Multitasking as multisensory behavior: Revisiting media multitasking in the perspective of media ecology theory. Computers in Human Behavior, 104, 106151.

Taryam, M., Alawadhi, D., Aburayya, A., Albaqa'een, A., Alfarsi, A., Makki, I., Rahmani, N., Alshurideh, M. \& Salloum, S. A. (2020). Effectiveness of not quarantining passengers after having a negative COVID-19 PCR test at arrival to dubai airports. Systematic Reviews in Pharmacy, 11(11), 1384-1395. https://doi.org/10.31838/srp.2020.11.197.

Taryam, M., Alawadhi, D., Al Marzouqi, A., Aburayya, A., Albaqa'een, A., Alfarsi, A., Makki, I., Rahmani, N., Aljasmi, M., Mubarak, S., Salloum, S. A. \& Alaali, N. (2021). The impact of the covid-19 pandemic on the mental health status of healthcare providers in the primary health care sector in Dubai. Linguistica Antverpiensia, 21(2), 2995-3015.

Venkatesh, V.\& Bala, H. (2008). Technology acceptance model 3 and a research agenda on interventions. Decision Sciences, 39(2), 273-315.

Venkatesh, V. \& Davis, F. D. (2000). Theoretical extension of the Technology Acceptance Model: Four longitudinal field studies. Management Science. INFORMS, 46(2), 186-204.

Venkatesh, V., Morris, M., Davis, G. \& Davis, F. (2003). User acceptance of information technology: Toward a unified view. MIS quarterly, 425-478.

Wagner, K. \& Frier, S. (2021). Facebook Smart Glasses Coming 'Sooner Than Later' Without AR - Bloomberg. Bloomberg.

\section{Appendix}

Measurement scale

\begin{tabular}{|c|c|c|c|c|c|c|c|c|}
\hline & Statement & $\begin{array}{l}\text { Strongly } \\
\text { disagree }\end{array}$ & Disagree & $\begin{array}{c}\text { Somewhat } \\
\text { disagree }\end{array}$ & Neutral & $\begin{array}{c}\text { Somewhat } \\
\text { agree }\end{array}$ & Agree & $\begin{array}{c}\text { Strongly } \\
\text { agree }\end{array}$ \\
\hline 1 & Pre-Market Knowledge & 24.1 & 14.2 & 13.5 & 15.4 & 10.2 & 7.7 & 15 \\
\hline 2 & Social Norm & 20 & 12.6 & 17.1 & 22.4 & 11.8 & 7.3 & 8.9 \\
\hline 3 & Ease of use & 2.6 & 1.9 & 6.5 & 23.9 & 16.9 & 21.5 & 26.8 \\
\hline 4 & Image & 30.5 & 14.3 & 16.7 & 16.6 & 7.8 & 5.1 & 8.9 \\
\hline 5 & Usefulness & 4.1 & 4.4 & 8.2 & 25.8 & 20.6 & 17.9 & 18.9 \\
\hline 6 & Brand attitude & 34.1 & 16.2 & 11.9 & 13.7 & 8.5 & 6.3 & 9.2 \\
\hline 7 & Other's privacy & 51.4 & 14.7 & 8.5 & 10.8 & 5.6 & 4.3 & 4.8 \\
\hline 8 & Multitasking & 5.3 & 5.3 & 11.6 & 27.6 & 19.5 & 14.8 & 15.9 \\
\hline 9 & Own privacy & 18.1 & 16.4 & 14.8 & 20.1 & 14 & 7.2 & 9.4 \\
\hline 10 & Enjoyment & 3.1 & 2.9 & 5.1 & 14 & 18.1 & 22 & 34.8 \\
\hline 11 & Tech. Innovativeness & 8.2 & 9.7 & 8.2 & 17.9 & 17.7 & 12.8 & 25.4 \\
\hline 12 & Adoption & 25.3 & 16 & 15.2 & 17.9 & 11.3 & 6 & 8.4 \\
\hline
\end{tabular}

1. Knowledge about smart glasses

I have good knowledge about smart Augmented Reality glasses and know the difference between them and لإي معرفة جيدة عن نظار ات الو اقع المعزز الذكية وأعرف الفرق بينها وبين نظار ات الواقع الافتراضي - Virtual Reality glasses

\section{Social norms}

I'll wear smart glasses when my peers start wearing them - سأرتدي النظار ات الذكية عندما يبدأ أقر اني بارتدائها

\section{Expected ease of use}

Smart glasses will be easy to use - ستكون النظار ات الذكية سهلة الاستخدام

\section{Self-presentation benefits}

Wearing smart glasses expresses my personality - سأرتدي النظار ات الذكية لأن ذلك سيكون تعبيرًا عن شخصيتي

\section{Usefulness}

Using smart glasses will make my daily tasks easier and faster - النظار ات الذكية ستجعل مهامي اليومية أسهل و أسر ع

\section{Brand attitude}

I'd only wear smart glasses if they were made by my favorite company - سأرتدي نظار ات ذكية فقط إذا كانت قامت شركتي المفضلة بصنعها 
7. Privacy brand image

I trust the company that produces smart glasses to protect my data - أثق بالشركة المنتجة للنظار ات الذكية في حماية بياناتي

8. Other privacy

I will wear smart glasses even if they violate social norms and other people's privacy - وأرتدي النظار ات الذكية حتى الأى ولو خالفت الأعر اف الاجتماعبة وخصوصيات الآخرين.

\section{Multitasking}

Smart glasses will enable me to free up my hands to multitask - النظار ات الذكية ستمكني من تحرير يدي للقيام بمهام متعددة

10. Technology innovativeness

I love buying and trying new technology products - أهتم باقتناء وتجربة المنتجات التكنولوجية الجديدة

\section{Enjoyment}

Smart glasses will enhance the learning experience and make it more fun - النظار ات الذكية ستعزز من تجربة التعليم وتجعله أكثر متعة

12. Adoption intention

I will be among the first to buy smart glasses - سأكون من أو ائل من يقتني النظار ات الذكية

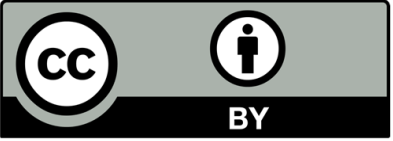

(C) 2022 by the authors; licensee Growing Science, Canada. This is an open access article distributed under the terms and conditions of the Creative Commons Attribution (CC-BY) license (http://creativecommons.org/licenses/by/4.0/). 